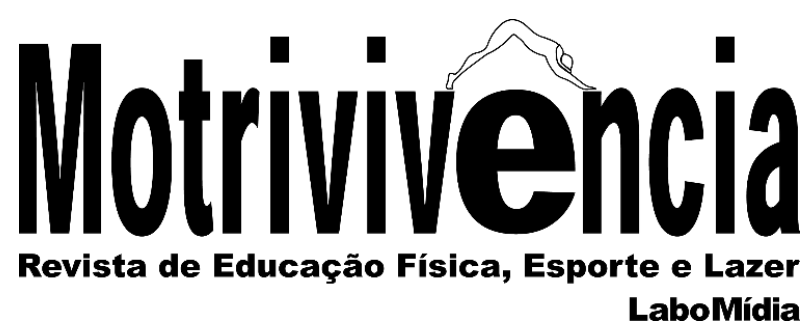

\title{
Um mapeamento de teses e dissertações sobre ginástica rítmica no Brasil
}

\section{RESUMO}

A visibilidade e a prática da Ginástica Rítmica (GR) têm crescido dentro dos países e tem instigado novas produções científicas. Diante disso, o presente estudo tem como objetivo identificar o perfil da produção acadêmico-científica sobre a Ginástica Rítmica indexada na Biblioteca Digital Brasileira de Teses e Dissertações (BDTD) e no banco de dados de teses e dissertações da CAPES. O caminho metodológico percorrido possui caráter exploratório e descritivo. Procurou-se evidenciar e caracterizar as instituições envolvidas nas produções sobre a modalidade e identificar quais são os enfoques temáticos. O escopo do estudo foi composto por 42 produções que utilizaram a GR como objeto de estudo, no período de 1988-2019. Como os assuntos mais pesquisados, encontrou-se os vinculados à saúde, treinamento, história, estética e formação profissional. Esses cinco assuntos encontrados foram analisados através do Modelo Analítico dos 5E's de Marchi Júnior (2015). Ao final, o presente estudo pôde contribuir com o meio acadêmico ao mapear as teses e dissertações que abordam a Ginástica Rítmica no Brasil, evidenciando as vertentes menos investigadas e, assim, passíveis de serem temas de novas pesquisas.

PALAVRAS-CHAVE: Ginástica rítmica; Produção do conhecimento; Mapeamento; Modelo analítico dos E's; Brasil

\section{Jéssica Gomes Nunes}

Graduada em Educação Física

Universidade Federal do Paraná,

Departamento de Educação Física, Curitiba, Brasil

jeh_gomesnunes@hotmail.com

https://orcid.org/0000-0002-5850-1719

Letícia Cristina Lima Moraes

Mestra em Educação Física Universidade Federal do Paraná, Departamento de Educação Física, Curitiba, Brasil letsmoraes96@gmail.com https://orcid.org/0000-0001-9444-8735

Wanderley Marchi Júnior

Doutor em Educação Física Universidade Federal do Paraná, Departamento de Educação Física, Curitiba, Brasil marchijr@ufpr.br https://orcid.org/0000-0002-4911-9702 


\title{
A mapping of theses and dissertations about rhythmic gymnastics in Brazil
}

\begin{abstract}
The visibility and practice of Rhythmic Gymnastics (RG) has grown within countries and has instigated new scientific productions. Therefore, this study aims to identify the profile of the academic-scientific production on Rhythmic Gymnastics indexed in the Brazilian Digital Library of Theses and Dissertations (BDTD) and in the CAPES theses and dissertations database. The methodological path followed has an exploratory and descriptive character. The aim was to evidence and characterize the institutions involved in the productions about the modality and to identify which are the thematic focuses. The scope of the study was composed of 42 productions that used RG as an object of study, in the period 1988-2019. The most researched subjects were those related to health, training, history, aesthetics, and professional training. These five subjects were analyzed using the 5E's Analytical Model of Marchi Júnior (2015). In the end, this study could contribute to the academic environment by mapping the theses and dissertations that address Rhythmic Gymnastics in Brazil, highlighting the less investigated aspects and, thus, likely to be subjects of new research.
\end{abstract}

KEYWORDS: Rhythmic gymnastics; Knowledge production; Mapping; 5E's analytical model; Brazil

\section{Un mapeo de tesis y disertaciones sobre la gimnasia rítmica en Brasil}

\section{RESUMEN}

La visibilidad y la práctica de la Gimnasia Rítmica (GR) ha crecido dentro de los países y ha impulsado nuevas producciones científicas. Por lo tanto, este estudio tiene como objetivo identificar el perfil de la producción académico-científica sobre Gimnasia Rítmica indexada en la Biblioteca Digital Brasileña de Tesis y Disertaciones (BDTD) y en la base de datos de tesis y disertaciones del CAPES. El camino metodológico seguido tiene un carácter exploratorio y descriptivo. Se buscó evidenciar y caracterizar las instituciones involucradas en las producciones sobre la modalidad e identificar cuáles son los focos temáticos. El ámbito del estudio estuvo compuesto por 42 producciones que utilizaron la RG como objeto de estudio, en el período 1988-2019. Como temas más investigados, se encontraron los vinculados a la salud, la formación, la historia, la estética y la formación profesional. Estos cinco temas encontrados fueron analizados a través del Modelo Analítico de las 5E's de Marchi Júnior (2015). Al final, este estudio podría contribuir con el entorno académico para mapear las tesis y disertaciones que abordan la Gimnasia Rítmica en Brasil, destacando los aspectos menos investigados $\mathrm{y}$, por lo tanto, susceptibles de ser temas de nuevas investigaciones.

PALABRAS-CLAVE: Gimnasia rítmica; Producción de conocimiento; Mapeo; Modelo analítico de las 5E's; Brasil. 


\section{INTRODUÇÃO}

Segundo Antualpa (2011), na década de 90, a Ginástica Rítmica (GR) brasileira passou a demonstrar um crescimento nos resultados em campeonatos internacionais conquistados em jogos sulamericanos e pan-americanos da modalidade. Em virtude desses resultados, de acordo com a autora, a mídia passou a dar maior visibilidade à Ginástica Rítmica, culminando em um maior interesse do público. Além disso, ampliando a qualificação da prática no país, muitos treinadores(as) estrangeiros(as) vieram para o Brasil auxiliar os treinamentos da seleção individual e de conjunto. Com esse acompanhamento estrangeiro, percebeu-se uma melhora na performance das ginastas representantes do Brasil, em ambas categorias.

Mesmo sabendo que as vindas desses treinadores(as) estrangeiros(as) tenham auxiliado na melhora técnica das ginastas brasileiras, Antualpa (2011) aponta que para uma melhor compreensão e sistematização da Ginástica Rítmica, estudos acerca deste subcampo ${ }^{1}$ ampliam possibilidades de aperfeiçoamentos técnicos, organizacionais e analíticos pertinentes a esta modalidade. Além disso, vale ressaltar que as ginásticas fazem parte do currículo do curso de Educação Física no Brasil, gerando a demanda de estudos sobre essas práticas em todos os níveis de formações (graduação, mestrado e doutorado) para suprir as necessidades práticas e teóricas das modalidades. Porém, mesmo com o crescimento da visibilidade, de praticantes, de resultados nacionais e internacionais, Antualpa (2011) aponta que a produção de conhecimento sobre a GR nem sempre acompanha esses índices.

Diversos mapeamentos e análises das produções de conhecimento sobre a temática das ginásticas em geral já foram realizadas. Entretanto, apenas um aborda as produções acerca da GR em específico, focando apenas nos artigos publicados (MORAES et al., 2019). Todavia, vale lembrar que com o crescimento da visibilidade, resultados e de praticantes de GR no Brasil, tem-se surgido inquietações e investigações de pesquisadores de diversas áreas (LOURENÇO, 2003). Dessa forma, realizar estudos do tipo "estado da arte" se destacam, pois propiciam a análise da produção acadêmica em determinada área e/ou em um período estabelecido que dissemina objetos, temas, metodologias, tipos de pesquisa - dentre outros aspectos -, indicando caminhos para melhorar e fomentar as necessidades de pesquisa sobre um tópico específico(SIMÕES et al., 2016).

Portanto, sabendo que teses e dissertações são trabalhos mais extensos que artigos e, consequentemente, trazem um aprofundamento maior sobre o objeto de estudo, esse artigo traz como

\footnotetext{
${ }^{11}$ Essa delimitação de subcampo advém dos pressupostos teóricos de Pierre Bourdieu (1990), em que dentro de um campo, e neste caso, do campo esportivo, existem espaços menores, denominados subcampos, que mantém, mesmo que em menor escala, as dinâmicas do qual está inserido. Assim, a Ginástica Rítmica será referida como um subcampo do campo esportivo. Para maiores leituras e reflexões sobre a Ginástica Rítmica como um subcampo, ler Paz, Souza e Barbosa-Rinaldi (2018). A leitura e análise de modalidades esportivas como subcampo também pode ser vista em Marchi Júnior (2017).
} 
questão norteadora a seguinte pergunta: Qual é o perfil da produção acadêmico-científica sobre Ginástica Rítmica em dissertações e teses brasileiras? Enquanto o objetivo geral é identificar o perfil da produção acadêmico-científica sobre a Ginástica Rítmica indexada na Biblioteca Digital Brasileira de Teses e Dissertações (BDTD) e no banco de dados de teses e dissertações da CAPES. Além disso, terá os seguintes objetivos específicos: a) evidenciar e caracterizar as instituições envolvidas nas produções acadêmicas sobre a GR e b) identificar quais são os enfoques temáticos nas produções acadêmicas-científicas, analisando-os pelo modelo analítico proposto por Marchi Júnior (2015).

Adiante será apresentado o caminho metodológico percorrido, descrevendo em sua integralidade o processo realizado para a efetivação desta pesquisa e, posteriormente, será realizada a descrição e análise dos dados obtidos na pesquisa, constituindo um perfil da produção acadêmicocientífica em teses e dissertações brasileiras relativas à Ginástica Rítmica do Brasil.

\section{Material e métodos}

O presente artigo possui caráter exploratório e descritivo com o propósito de oferecer um panorama qualitativo e quantitativo sobre as teses e dissertações sobre Ginástica Rítmica produzidas no Brasil. De acordo com Gil (2008), pesquisas exploratórias são desenvolvidas com o objetivo de proporcionar visão geral, do tipo aproximativo, acerca de determinado fato. Este tipo de pesquisa é realizado especialmente quando o tema escolhido é pouco explorado e torna-se difícil formular hipóteses precisas e operacionalizáveis.

As catalogações de teses e dissertações brasileiras foram realizadas por meio do Catálogo de Teses e Dissertações da Coordenação de Aperfeiçoamento de Pessoal de Nível Superior (CAPES) e da Biblioteca Digital de Teses e Dissertações (BDTD). A delimitação destas duas bases ocorreu devido a elas englobarem, em plataformas completas, os sistemas de informações de teses e dissertações do país, facilitando a busca e acesso aos documentos das instituições. Segundo o histórico fornecido pela CAPES, em julho de 2002, a Coordenação de Aperfeiçoamento de Pessoal de Nível Superior disponibilizou o catálogo de teses com o objetivo de facilitar o acesso a informações de referências e resumos das teses/dissertações defendidas em programas de pós-graduação do Brasil. No final do ano de 2002 foi criada a BDTD, pelo Instituto Brasileiro de Informação em Ciência e Tecnologia, o qual mantem até hoje o Programa da Biblioteca Digital Brasileira com apoio da Financiadora de Estudos e Pesquisas.

Em termos de nomenclaturas, segundo Boaventura (2016), durante o percurso histórico da Ginástica Rítmica, a modalidade recebeu várias denominações: Ginástica Moderna (1963), Ginástica Feminina Moderna, Ginástica Rítmica Moderna (1972), Ginástica Rítmica Desportiva - GRD (1975) 
e Ginástica Rítmica - GR (1998). Partindo dessas denominações, para as pesquisas nas bases de dados foi utilizado o descritor "Ginástica Rítmica", pois com ele foi possível captar as denominações de Ginástica Rítmica Desportiva (GRD) e de Ginástica Rítmica Masculina. Também foram utilizados os descritores "Ginástica Moderna" e "Ginástica Rítmica Feminina”, porém, não foi encontrado nenhum material com essa terminologia. Não se delimitou um recorte temporal inicial, com a intenção de encontrar os trabalhos completos disponíveis mais antigos sobre GR, enquanto o recorte final se deu até o mês de março de 2020, período de catalogação desses materiais. Ao final, a delimitação temporal foi de 1988 (data do primeiro trabalho encontrado) até 2019 (última produção encontrada até o final da catalogação).

Como critérios de inclusão, foram utilizados três com o propósito de buscar produções que utilizaram a Ginástica Rítmica como objeto de estudo nas bases de dados selecionadas. Assim, para serem consideradas para o estudo foram feitas leituras parciais das teses e dissertações. As mesmas deveriam cumprir os seguintes critérios pré-estabelecidos: I) deveriam ser estudos de brasileiros(as), II) possuir o enfoque voltado para a GR - a verificação se deu a partir da presença do termo "Ginástica Rítmica" no título, palavras-chave e/ou no resumo, III) oferecer acesso aberto e completo da tese/dissertação. Como critério de exclusão, considerou-se que os estudos que colocassem a Ginástica Rítmica simultaneamente com outras modalidades esportivas seriam excluídos, assim como aqueles que não continham a Ginástica Rítmica como foco central.

Depois de selecionar as teses e dissertações, foram catalogadas as produções acadêmicas em uma planilha eletrônica que contém os campos para preencher com as seguintes informações referentes aos estudos: a) base em que foi encontrada; b) título do trabalho; c) dissertação/tese; d) nome do autor; e) relação do autor com a modalidade; f) graduação; g) programa de pós-graduação; h) instituição; i) assunto e j) local abordado na pesquisa² ${ }^{2}$

Com a intenção de coletar as informações relacionadas aos autores foi utilizada a plataforma do Currículo Lattes e, quando necessário, páginas online das instituições de ensino. Autores que não tinham vinculado seus currículos ao site ou até mesmo atualizados, dificultaram a obtenção das informações, podendo ser uma das limitações do estudo.

Em relação ao que se denominou "assunto", se refere ao que foi apresentado contextualmente e analiticamente nas teses e dissertações, ou seja, foram delimitados os tópicos temáticos centrais que foram discutidos em cada trabalho, como saúde, treinamento, estética, etc. Essa codificação foi realizada baseando-se principalmente na leitura do título, palavras-chave e do resumo dos materiais

\footnotetext{
${ }^{2}$ Caso a pesquisa fosse desenvolvida em mais de um local ou não tivesse uma delimitação espacial no território nacional, o termo utilizado para codificar foi "Brasil".
} 
analisados, pois compreende-se que esses elementos textuais traduzem a ideia central do que será trabalhado pelos autores (DART, 2014; SEIPPEL, 2018).

Em alguns textos aconteciam casos de sobreposição de temas trabalhados, por exemplo, quando as palavras "lesão", "prevenção" e "saúde" apareceram no título, resumo e palavras-chave, foram codificadas uma única vez sob a categoria temática de "saúde". A intenção de aglomerar e codificar essas informações foi de assegurar a identificação das abordagens de estudo dominantes nas teses e dissertações encontradas, possibilitando a visualização dos interesses daqueles que possuem a GR como objeto de estudo.

Para a identificação do local abordado, foi realizada a leitura do título, resumo e, quando necessário, da introdução e metodologia das teses e dissertações. Após a localização da informação, a delimitação espacial foi inserida na planilha, como já mencionado. O objetivo de quantificar e analisar esse dado é de conseguir oferecer um panorama sobre quais locais são mais investigados.

Após essa fase manual de catalogação na planilha eletrônica, os dados representados por palavras como os assuntos e locais investigados mais frequentes foram organizados em arquivos de texto separados para que os espaços entre as palavras fossem retirados ${ }^{3}$. Após esse processo, os arquivos de textos editados foram inseridos no programa Nvivo 12 Plus, para utilizar a ferramenta de representação dos dados por meio de uma nuvem de palavras, realizada por meio de uma consulta proporcionada automaticamente pelo software. Essa ferramenta proporciona a visualização dos termos que compareceram com maior frequência e, sendo assim, quanto maior for a fonte da palavra representada, mais vezes a palavra apareceu nos dados catalogados. No entanto, vale lembrar que esses dados também terão suporte quantitativo quando necessário.

A análise dos dados referente aos assuntos mais encontrados, se baseou no Modelo Analítico dos 5E's proposto por Wanderley Marchi Júnior (2015). Segundo Fermino et al. (2018), o modelo analítico do esporte proposto por Marchi Júnior apresenta-se como uma possibilidade interessante, uma vez que busca tratar das diferentes tendências, relações e consequências do fenômeno esportivo na sociedade contemporânea. O modelo contém cinco dimensões analíticas do esporte: Educação, Espetáculo, Estética, Emoção e Ética. A explicação de cada dimensão será realizada na sessão de discussão e análise dos resultados.

Sendo assim, para uma análise sobre os assuntos encontrados no escopo deste estudo, utilizamos as dimensões que melhor se correlacionam com o assunto central dos trabalhos. Essa relação das dimensões analíticas com os assuntos mais tratados se deu com a leitura parcial das teses e dissertações encontradas. Ao final, focou-se em apenas três dimensões de análises: Educação, Ética e

\footnotetext{
${ }^{3}$ Essa estratégia foi realizada por opção dos pesquisadores(as) visto que o software utilizado separa as palavras ao representa-las na nuvem de palavras. Assim, os assuntos e locais irão ser apresentados sem espaços entre as palavras.
} 
Estética, uma vez que elas melhor representavam os conteúdos abordados pelos trabalhos que fizeram parte deste estudo.

A seguir, serão abordados os dados gerais de publicação desses trabalhos, as áreas e instituições que tiveram autores investigando a Ginástica Rítmica, os locais que mais foram citados oferecendo um panorama das regiões mais estudadas e que estão ligadas à modalidade, e os assuntos mais predominantes nas teses e dissertações, sendo analisados por meio do modelo de Marchi Júnior (2015).

\section{Resultados e discussão}

Após as buscas das teses e dissertações referentes à Ginástica Rítmica no Brasil, catalogou-se 42 pesquisas com esse enfoque. Como foi descrito na metodologia, um dos campos preenchidos da planilha eletrônica foi o do ano de defesa. Para entender como foi a periodicidade dessas publicações, gerou-se o gráfico a seguir.

Figura 1 - Número de teses e dissertações publicadas por ano sobre Ginástica Rítmica.

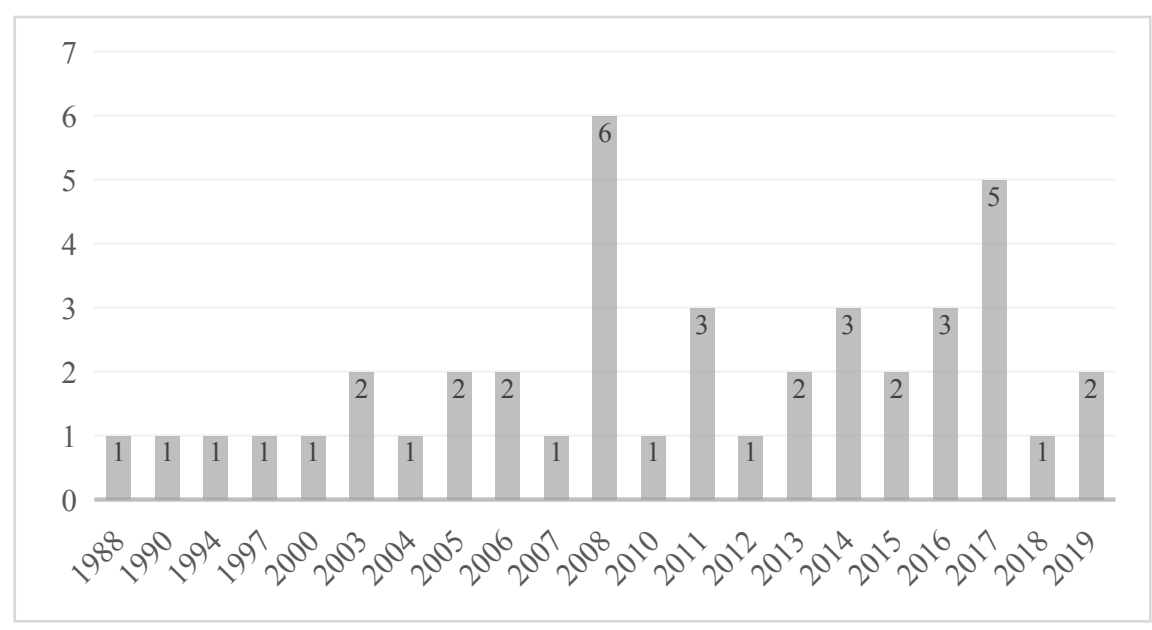

Fonte: elaboração própria do(a/as/s) autor(a/as/es) (2020).

O gráfico acima contém a distribuição das teses e dissertações catalogadas no período de 1988 a 2019. Até 2003 as pesquisas eram esporádicas, contabilizando uma em cada ano que foi localizada. Após o ano de 2003 ocorreu uma constância nas publicações, pelo menos uma pesquisa era publicada, exceto pelo ano de 2009, que não se teve publicações de teses e dissertações referentes ao tema mesmo tendo sucedido um ano (2008) com o maior número de produções.

Visto que existe uma oscilação na quantidade de publicações, subentende-se que não há uma padronização ou até mesmo uma agenda de pesquisa consolidada referente a Ginástica Rítmica. 
Entretanto, nota-se que em dois anos distintos, 2008 e 2017, as produções sobre a modalidade cresceram. Uma hipótese para o aumento nestes anos, pode ser devido aos resultados obtidos em competições nos anos anteriores que possibilitaram uma maior visibilidade da modalidade e, por consequência, o interesse em pesquisar esse esporte. Outra hipótese surgiu após a verificação da relação dos autores destes anos com a modalidade, no qual dentre os 11 autores encontrados - oito deles possuem relações com a GR (ex.: ex-atletas, árbitras, técnicas e fisioterapeutas de atletas).

Essa relação específica dos autores das teses e dissertações com a GR pode ser analisada por meio da teoria bourdieusiana $(2009 ; 1996)$ e dos seus conceitos basilares de campo - e, nesse caso, de subcampo também - e habitus, que visa estabelecer a relação entre as estruturas objetivas e as estruturas incorporadas, respectivamente. Assim sendo, de início, deve-se levar em consideração que um campo é, para Bourdieu (1996), um microcosmo incluído no macrocosmo constituído pelo espaço social global, dotado de autonomia relativa, com lógicas e necessidades próprias, específicas, com interesses e disputas irredutíveis ao funcionamento de outros campos. Assim, para analisar a GR, primeiramente localizamos ${ }^{4}$ o campo esportivo, que possui em seu interior formas de disputas, lutas e concorrência na busca pela hegemonia de determinadas práticas, e a distinção social proporcionada às pessoas envolvidas (MARCHI JÚNIOR, 2017). No interior desse campo, encontra-se o subcampo da Ginástica Rítmica que, de acordo com Paz, Souza e Barbosa-Rinaldi (2018), possui suas regras que lhe garantem relativa autonomia, conseguindo organizar suas dinâmicas, ações e estilizações específicas da modalidade. Dessa forma, ao estar inserido nesse subcampo estruturado, os agentes passam a possuir "princípios geradores de práticas distintas e distintivas", isto é, um habitus incorporado (BOURDIEU, 1996, p.22). Em outras palavras, é possível dizer que, ao pertencer ou ter pertencido a esse espaço social específico, os autores incorporaram um sistema de disposições, permanentes e geradoras de práticas e representações e que, ao passarem a ocupar posições no campo científico, os pesquisadores conseguiram relacionar esse habitus incorporado com os interesses e trunfos disputados no campo científico (BOURDIEU, 2004).

A seguir, para entender mais sobre os picos de produções citados anteriormente, foi elaborado um gráfico que evidencia as distribuições das dissertações e teses no recorte de 1988-2019, com objetivo de verificar individualmente cada tipo de pesquisa.

Figura 2 - Distribuição de teses e dissertações por ano.

\footnotetext{
${ }^{4}$ Wacquant (2005) sugere que a primeira operação para análise de um campo é localizar o microcosmo dentro do campo de poder, isto é, na teia de instituições na qual circulam os poderes econômicos, políticos e culturais que a classe dominante luta para conservar. Posteriormente deve-se realizar uma topologia da estrutura do campo, desvendando a estruturação das relações. Neste ponto, de acordo com Bourdieu (2003), no caso do campo esportivo, se faz necessário o reconhecimento da posição que determinada modalidade ocupa no espaço dos esportes.
} 


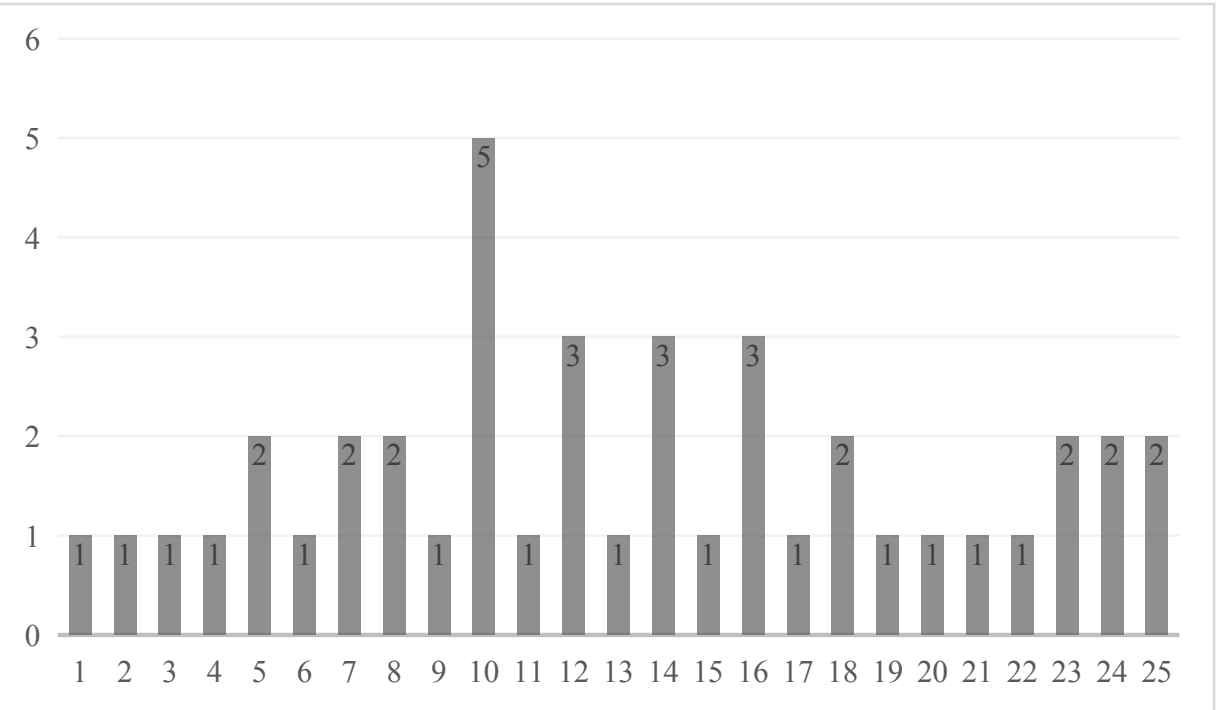

Fonte: elaboração própria do(a/as/s) autor(a/as/es) (2020).

Analisando este gráfico é perceptível visualizar que as maiores quantidades de publicações são de dissertações, tanto de modo geral quanto referente aos picos já comentados. Do total de 42 produções, 10 são teses e 32 são dissertações, e comparando esses números é possível compreender que essa diferença ocorre por conta do tempo máximo destinado para a produção de uma tese, que é de quatro anos, enquanto para o mestrado o tempo é de dois anos.

Essa distribuição possibilita visualizar como está a concentração das produções brasileiras sobre a modalidade. Ademais, surgiu o questionamento sobre a formação inicial dos autores que se dedicaram às teses e dissertações encontradas. Para isso, com o objetivo de verificar a formação dos autores e assim identificar relações com a modalidade e as temáticas definidas na pesquisa, a tabela a seguir ilustra as graduações cursadas por cada autor.

Quadro 1 - Graduação dos(as) autores(as).

\begin{tabular}{|l|c|}
\hline Graduação do autor & Quantidade de autores \\
\hline Educação Física & 36 \\
\hline Fisioterapia & 3 \\
\hline Psicologia & 2 \\
\hline N.E* & 1 \\
\hline Total Geral & $\mathbf{4 2}$ \\
\hline Fonte: elaboração própria do(a/as/s) autor(a/as/es) (2020).
\end{tabular}

Fonte: elaboração própria do(a/as/s) autor(a/as/es) (2020). N.E*: Não encontrado.

A tabela acima mostra quais foram os cursos de graduação que os autores cursaram. Lembrando que essas informações foram retiradas da base de dados do Currículo Lattes, plataforma que contempla as informações de pesquisadores do Brasil, na qual cada autor alimenta seu currículo nessa interface online. Sabendo disso, é possível visualizar na tabela que apenas 1 dos autores não 
informou sua graduação. Entretanto, analisando os demais dados encontrados, verifica-se que a maioria dos autores possuem graduação na área de Educação Física.

Uma hipótese para esse resultado, é que por ser uma temática ligada à uma modalidade esportiva, a maior quantidade de pesquisas se encontra nos cursos de Educação Física, tanto na área de bacharelado quanto na área de licenciatura. Além disso, e corroborando com Boaventura (2016), a escolha pelo curso de Educação Física está muito ligada às experiências na Ginástica Rítmica que os autores tiveram e que têm potencial de influenciar nas escolhas profissionais. Isso ocorre ao enxergar na graduação em Educação Física a perspectiva de permanecer no campo esportivo e, de certo modo, no subcampo da GR, ao trata-la como objeto de estudo no campo científico e/ou ao observarem a possibilidade de se tornarem professores(as)/técnicos(as) a partir dessa formação de ensino superior que habilita para tal função.

Outros cursos apareceram com poucas produções, como é o caso da Fisioterapia e da Psicologia, áreas que possuem atuação direta quando se trata de atletas/ginastas. Segundo Mazzei et al. (2012), um Centro de Treinamento deve contar com uma equipe técnica esportiva multidisciplinar, dentre eles: preparadores físicos, fisioterapeutas, nutricionistas e psicólogos, se tornando necessário principalmente em um treinamento de alto nível, como o de uma seleção nacional. A presença desses profissionais contribui para o treinamento das ginastas para, por exemplo, prevenção e tratamento de lesões, além do acompanhamento psicológico e nutricional requerido. O envolvimento e investimento dessas áreas em pesquisas específicas para a modalidade, nesse sentido, também é de extrema importância e que deve ser estimulada.

Sendo assim, após visualizar a distribuição anual de produções e as áreas que mais pesquisam a modalidade, encontra-se a necessidade de identificar as instituições que mais produzem pesquisas sobre a Ginástica Rítmica. Nesse sentido, temos a tabela 2 que evidencia quais são essas instituições.

Quadro 2 - Instituições vinculadas às teses e dissertações sobre Ginástica Rítmica. 


\begin{tabular}{|l|l|l|}
\hline Instituição & Região & $\begin{array}{l}\text { Quantidade } \\
\text { acadêmicos }\end{array}$ \\
\hline Universidade Federal de Santa Catarina & Sul & 7 \\
\hline Universidade Federal do Rio Grande do Sul & Sul & 6 \\
\hline Universidade Estadual de Campinas & Sudeste & 6 \\
\hline Universidade Federal do Rio Grande do Norte & Nordeste & 3 \\
\hline Universidade de São Paulo & Sudeste & 2 \\
\hline Universidade Metodista de Piracicaba & Sudeste & 2 \\
\hline Universidade Estadual Paulista & Sudeste & 2 \\
\hline Universidade Estadual de Maringá & Sul & 1 \\
\hline Universidade Federal do Rio de Janeiro & Sudeste & 1 \\
\hline Universidade Federal do Pará & Norte & 1 \\
\hline Universidade Federal do Espírito Santo & Sudeste & 1 \\
\hline Universidade Federal da Bahia & Nordeste & 1 \\
\hline Universidade Federal do Paraná & Sul & 1 \\
\hline Universidade do Estado do Rio de Janeiro & Sudeste & 1 \\
\hline Universidade Federal de Minas Gerais & Sudeste & 1 \\
\hline Universidade Federal de Juiz de Fora & Sudeste & 1 \\
\hline Universidade Federal de São Paulo & Sudeste & \\
\hline Universidade Federal do Amazonas & Norte & 1 \\
\hline Centro Universitário La Salle & Sul & \\
\hline Total Geral & & $\mathbf{4 2}$ \\
\hline
\end{tabular}

Fonte: elaboração própria do(a/as/s) autor(a/as/es) (2020).

Visualizando a tabela acima, nota-se que três instituições se destacam em número de produções, sendo elas: Universidade Federal de Santa Catarina (região sul), Universidade Federal do Rio Grande do Sul (região sul) e a Universidade Estadual de Campinas (região sudeste). Verifica-se que dentre esses destaques, duas são da região sul. Sendo assim, ao agrupar por regiões todas as instituições analisadas, encontra-se uma predominância da região sudeste (19 produções) e região sul (17 produções), com um percentual de $85,7 \%$ das produções referentes à Ginástica Rítmica.

Durante a catalogação das teses e dissertações foram registrados os nomes dos programas de pós-graduação que cada autor cursou. Na Universidade Federal de Santa Catarina (UFSC) quatro trabalhos realizados no Programa de Pós-Graduação em Educação Física, um em Educação, um em Ciência do Movimento Humano (nome do programa no ano de 1997) e um no Programa de PósGraduação Interdisciplinar em Ciências Humanas. Nenhuma das linhas de pesquisas presentes nas áreas de concentração dos programas possuem a ginástica como tema central ${ }^{5}$, mas todas a abordam como objeto de estudo, seja pela perspectiva de treinamento, saúde e/ou discussões socioculturais.

\footnotetext{
${ }^{5}$ A busca se deu a partir da leitura dos nomes das linhas de pesquisa e de suas respectivas descrições nos sites institucionais. O critério para verificar se abordava a ginástica especificamente foi a localização ou não do termo "Ginástica Rítmica” nos nomes das linhas ou nas descrições.
} 
Na Universidade Estadual de Campinas (UNICAMP) três das teses e dissertações foram oriundas do Programa de Pós-Graduação em Educação Física, duas do Programa de Pós-Graduação em Saúde da Criança e do Adolescente e uma no Programa de Pós-Graduação em Ciência da Nutrição e do Esporte e Metabolismo. Nesta instituição possuem linhas de pesquisas voltadas a crianças/atletas, como é o exemplo da linha de pesquisa em Crescimento e Endocrinologia da Criança e do Adolescente e a linha em Ciências do Esporte Aplicadas à Modelos Experimentais e Humanos. Vale lembrar que a ginástica possui praticantes de pouca idade (BOAVENTURA, 2016; CARDOSO, 2013), por isso as linhas de pesquisa acima são de interesse quando relacionadas à Ginástica Rítmica.

Ao analisar a plataforma online da instituição UNICAMP, mais precisamente na área específica da Faculdade de Educação Física, foi encontrado um grupo de pesquisa com o foco em ginástica. Este grupo vem desenvolvendo estudos e pesquisas, com o objetivo de contribuir na produção de conhecimento nesta área. Sua criação foi em 1993 e como parte de suas atividades, organizam-se cursos, palestras, encontros, seminários, viagens de estudo, intercâmbios e também a participação em dois dos principais eventos da área: Fórum Internacional de Ginástica Para Todos (FIGPT) e o Seminário Internacional de Ginástica Artística e Rítmica de Competição (SIGARC).

Outra instituição de destaque é a Universidade Federal do Rio Grande do Sul (UFRGS), na qual suas seis produções catalogadas são do Programa de Pós-Graduação em Ciência do Movimento Humano. Com áreas de concentração em Movimento Humano, Saúde e Performance, é possível perceber a pluralidade de abordagens que a GR como objeto de estudo oferece.

A seguir, podemos correlacionar as produções sobre a Ginástica Rítmica nestas instituições com a visibilidade da modalidade na cidade/estado ou até mesmo pela relação dos autores com a modalidade. Sendo assim, após verificar as instituições e regiões que mais se destacaram, foram analisados os locais em que os estudos se basearam. A figura a seguir ilustra os locais de estudo delimitado pelos autores, sendo os nomes centrais e de maior tamanho os que apareceram com maior frequência nas teses e dissertações encontradas.

Figura 3 - Locais investigados nas teses e dissertações sobre Ginástica Rítmica.

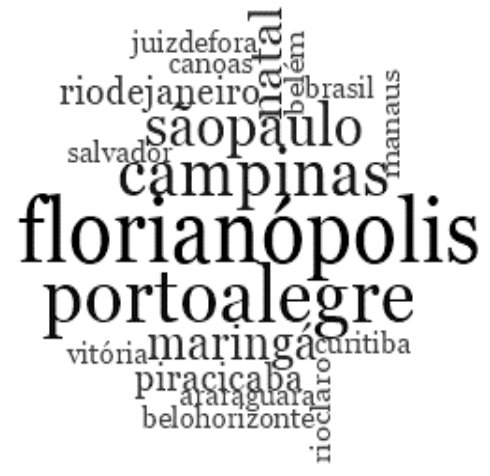

Fonte: elaboração própria do(a/as/s) autor(a/as/es) (2020). 
Esta nuvem de palavras ilustra quais são as cidades em que as pesquisas se basearam ${ }^{6}$. Na figura, os nomes em destaque são: Florianópolis com sete pesquisas, Porto Alegre com seis pesquisas e Campinas com cinco pesquisas. Outros locais como São Paulo, Maringá e Natal apareceram com mais de duas pesquisas, já as demais localizações apareceram com menos de dois trabalhos, por isso se encontram com tamanhos menores. É perceptível visualizar que os locais mais frequentes estão relacionados diretamente com as instituições que se destacaram na análise anterior. Possivelmente, esses locais se sobressaem por pertencerem a regiões com maior engajamento da modalidade nos seus estados. Segundo Lourenço (2015), o perfil das ginastas da seleção brasileira de conjuntos juvenil é oriundo de clubes da região sul do país (PR, SC e RS), sendo 83,3\% das ginastas entrevistadas e as demais, $16,7 \%$, da região sudeste (ES e SP).

Todavia, ao verificar a tabela de catalogação das produções analisadas, percebe-se que alguns locais estudados pelos autores estão desvinculados da região ${ }^{7}$ onde as instituições de ensino estão localizadas. Uma hipótese para esse dado é que por conta de alguns clubes brasileiros serem mais estruturados que outros (ANTUALPA, 2011), os mesmos acabam se tornando um foco de estudo de maior interesse e possibilidade de efetivação da pesquisa.

Por conseguinte, após analisar os locais estudados, as instituições de ensino dos autores e a graduação cursada por eles, iremos adentrar nos principais assuntos tratados nos estudos. A Figura 4 apresenta as palavras que representam os enfoques temáticos das produções científico-acadêmicas encontradas, codificadas após a leitura do título, palavras-chave e resumo - visto que esses elementos textuais são usualmente utilizados para traduzir os elementos centrais tratados (DART, 2014) -, e graficamente criada a partir da ferramenta de nuvem de palavras do Nvivo 12 Plus. É importante salientar que essa codificação é de difícil realização visto a ampla gama de assuntos tratados em trabalhos de tese/dissertação, podendo ser considerada, inclusive, uma das limitações desse estudo. Entretanto, essa codificação inicial foi necessária para que pudessem ser analisadas, posteriormente, pelas lentes do Modelo Analítico de Marchi Júnior (2015).

Figura 4 - Assuntos mais tratados nas teses e dissertações sobre Ginástica Rítmica.

\footnotetext{
${ }^{6}$ Ressalta-se que o local "Brasil" se refere a um único estudo, no qual foi baseado em 5 treinadoras/árbitras que não foram descritos de qual estado cada uma pertencia. Esse critério também seria adotado caso o estudo envolvesse mais de um local. Além disso, na figura estão representados apenas os locais que apareceram mais de duas vezes em teses/dissertações.

${ }^{7}$ Um exemplo de direcionamento possível de autores para outras regiões é, por exemplo, quando se desenvolve um estudo com atletas da categoria adulto do conjunto de GR - estes teriam que ir até a sede localizada em Aracaju (SE) caso não residissem na cidade.
} 


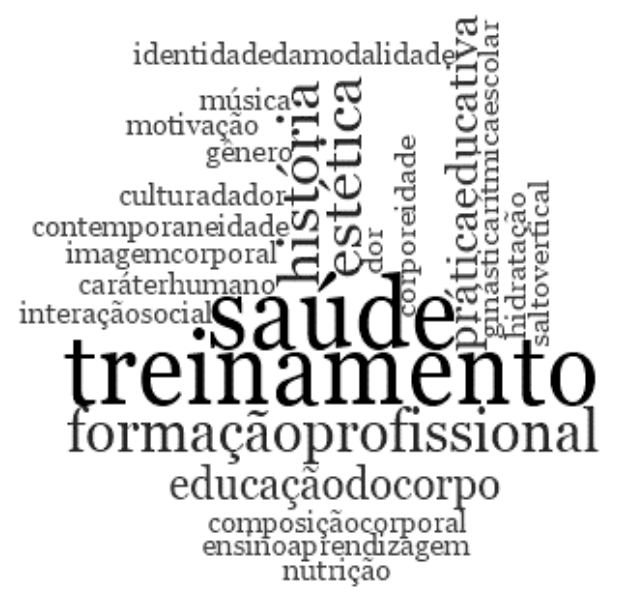

Fonte: elaboração própria do(a/as/s) autor(a/as/es) (2020).

A figura acima serve para ilustrar a totalidade dos trabalhos encontrados, apresentando os seus principais assuntos. Assim, como na nuvem de palavras anterior, as maiores palavras e que estão no centro da figura, são os assuntos que apareceram com maior frequência na planilha de catalogação dos dados. As palavras mais visíveis são: saúde, que representa seis do total de trabalhos localizados; treinamento, com cinco trabalhos; estética com quatro trabalhos; e história e formação profissional que correspondem cada um, a três trabalhos. Os demais assuntos presentes na nuvem de palavras apareceram menos de duas vezes e, para melhor detalhamento e análise das abordagens mais trabalhadas sobre GR, apenas os assuntos com mais de três ocorrências serão analisados. Essa delimitação foi realizada com a finalidade de detalhar e analisar os assuntos mais tratados, não sendo uma forma de menosprezar ou ignorar as demais produções.

Esses cinco assuntos encontrados serão descritos e analisados através do Modelo Analítico dos 5E's (MARCHI JÚNIOR, 2015), o qual possibilita tratar das diferentes tendências, relações e consequências dos fenômenos esportivos na sociedade contemporânea. Este modelo sugerido por Marchi Júnior, aborda as seguintes dimensões: 1) Emoção - dimensão que aborda situações que levam o ser humano a um intenso nível de excitação, tornando-se possível obter uma manifestação de um descontrole controlado das emoções; 2) Estética - dimensão que trata dos discursos que associam o esporte com o conceito de saúde e que apresenta de maneira obsessiva a busca pelo corpo perfeito com o objetivo de se enquadrar nos padrões estéticos ditados pela sociedade; 3) Ética - dimensão que analisa o esporte a partir de um conjunto de regras, valores e condutas; 4) Espetáculo - dimensão que observa tanto os processos estruturais (amadorismo, institucionalização e profissionalização do esporte) como a mercantilização e as relações econômicas envolvidas na espetacularização do esporte; 5) Educacional - faz a interconexão das diversas dimensões sociais do esporte numa perspectiva formativa. Esse modelo proporcionará, dessa forma, uma leitura relacional entre o esporte, nesse caso 
específico da GR, e a sociedade que está circunscrita também nas teses e dissertações encontradas no presente estudo.

Após verificar as relações dos trabalhos com os assuntos de saúde, treinamento, estética, história e formação profissional, delimitou-se que as dimensões que melhor englobam esses assuntos são: Estética, Ética e Educação. O quadro a seguir mostra a produção acadêmica codificada nos assuntos mais encontrados (como evidenciado anteriormente) que serão analisadas por meio do Modelo Analítico.

Quadro 3 - Teses e dissertações com os assuntos mais frequentes.

\begin{tabular}{|c|c|c|c|}
\hline Autores & $\begin{array}{l}\text { Natureza - } \\
\text { Ano }\end{array}$ & Título & Assuntos \\
\hline Cláudia Tarragô Candotti & $\begin{array}{l}\text { Dissertaçã } \\
\text { o - } 1997\end{array}$ & $\begin{array}{c}\text { Efeitos de um programa de relaxamento } \\
\text { muscular na dor lombar de atletas de Ginástica } \\
\text { Rítmica Desportiva: um estudo eletromiográfico }\end{array}$ & Saúde \\
\hline Anderson Simas Frutuoso & $\begin{array}{c}\text { Dissertaçã } \\
0-2014\end{array}$ & $\begin{array}{l}\text { Desequilíbrios e assimetrias de membros } \\
\text { inferiores em atletas de Ginástica Rítmica }\end{array}$ & Saúde \\
\hline Paula Barreiros Debien & $\begin{array}{c}\text { Dissertaçã } \\
0-2016\end{array}$ & $\begin{array}{l}\text { Monitoramento da carga de treinamento na } \\
\text { Ginástica Rítmica: efeitos no estado de } \\
\text { recuperação, perfil hormonal, resposta imune e } \\
\text { desempenho físico }\end{array}$ & Saúde \\
\hline $\begin{array}{l}\text { Fabiano Carlos do } \\
\text { Nascimento }\end{array}$ & $\begin{array}{c}\text { Dissertaçã } \\
0-2008\end{array}$ & $\begin{array}{c}\text { Avaliação da satisfação com o peso corporal e a } \\
\text { propensão às desordens alimentares em atletas } \\
\text { de Ginástica Rítmica de elite }\end{array}$ & Saúde \\
\hline Renan Codonhato & $\begin{array}{c}\text { Dissertaçã } \\
0-2017\end{array}$ & $\begin{array}{l}\text { Resiliência, estresse e lesões no contexto da } \\
\text { Ginástica Rítmica de elite }\end{array}$ & Saúde \\
\hline $\begin{array}{l}\text { Cristiane Teixeira Amaral } \\
\text { Camargo }\end{array}$ & $\begin{array}{l}\text { Tese - } \\
2013\end{array}$ & $\begin{array}{c}\text { Comportamento alimentar, massa óssea e } \\
\text { composição corporal em atletas de Ginástica } \\
\text { Rítmica em relação a idade cronológica e à } \\
\text { maturação somática } \\
\end{array}$ & Saúde \\
\hline Kamila Pimentel dos Santos & $\begin{array}{c}\text { Dissertaçã } \\
0-2019\end{array}$ & $\begin{array}{l}\text { Ginástica Rítmica: a questão do corpo ideal no } \\
\text { contexto amazônico }\end{array}$ & Estética \\
\hline $\begin{array}{l}\text { Hosana Cláudia Matias da } \\
\text { Costa Pereira }\end{array}$ & $\begin{array}{l}\text { Dissertaçã } \\
0-2013\end{array}$ & Ginástica Rítmica: um concerto para o corpo & Estética \\
\hline $\begin{array}{c}\text { Loreta Melo Bezerra } \\
\text { Cavalcanti }\end{array}$ & $\begin{array}{l}\text { Dissertaçã } \\
0-2008\end{array}$ & $\begin{array}{l}\text { Beleza e poder na Ginástica Rítmica: reflexões } \\
\text { para a Educação Física }\end{array}$ & Estética \\
\hline $\begin{array}{l}\text { Patrícia Luiza Bremer } \\
\text { Boaventura }\end{array}$ & $\begin{array}{l}\text { Tese }- \\
2016\end{array}$ & $\begin{array}{l}\text { Técnica, estética, educação: os usos } \\
\text { do corpo na Ginástica Rítmica }\end{array}$ & Estética \\
\hline Kizzy Fernandes Antualpa & $\begin{array}{l}\text { Dissertaçã } \\
0-2011\end{array}$ & $\begin{array}{c}\text { Centro de treinamento de Ginástica Rítmica no } \\
\text { Brasil: estruturas e programas }\end{array}$ & $\begin{array}{l}\text { Treinament } \\
\text { o }\end{array}$ \\
\hline Patrícia Silveira Fontana & $\begin{array}{l}\text { Tese - } \\
2015\end{array}$ & $\begin{array}{c}\text { A teoria da autodeterminação e o ambiente de } \\
\text { treino de Ginástica Rítmica: um modelo } \\
\text { motivacional teórico-explicativo }\end{array}$ & $\begin{array}{c}\text { Treinament } \\
\mathrm{o}\end{array}$ \\
\hline Kizzy Fernandes Antualpa & $\begin{array}{l}\text { Tese - } \\
2017\end{array}$ & $\begin{array}{c}\text { O efeito da estratégia de intensificação e } \\
\text { tapering nas respostas hormonais, } \\
\text { comportamentais, de desempenho, e na } \\
\text { imunidade da mucosa oral em jovens atletas de } \\
\text { Ginástica Rítmica }\end{array}$ & $\begin{array}{c}\text { Treinament } \\
\mathrm{o}\end{array}$ \\
\hline $\begin{array}{c}\text { Cynthia Cleusa Pasqua } \\
\text { Mayer Tibeau }\end{array}$ & $\begin{array}{c}\text { Dissertaçã } \\
0-1988\end{array}$ & $\begin{array}{c}\text { Ensino de Ginástica Rítmica Desportiva pelo } \\
\text { método global: viabilidade e eficácia }\end{array}$ & $\begin{array}{c}\text { Treinament } \\
\mathrm{o}\end{array}$ \\
\hline
\end{tabular}




\begin{tabular}{|c|c|c|c|}
\hline Priscila Martins Caçola & $\begin{array}{l}\text { Dissertaçã } \\
0-2006\end{array}$ & $\begin{array}{l}\text { Comparação entre as práticas em partes e como } \\
\text { um todo e a utilização de dicas na aprendizagem } \\
\text { motora de duas habilidades da Ginástica Rítmica }\end{array}$ & $\begin{array}{c}\text { Treinament } \\
\text { o }\end{array}$ \\
\hline Giovanna Sarôa & $\begin{array}{l}\text { Dissertaçã } \\
0-2005\end{array}$ & A história da Ginástica Rítmica em Campinas & História \\
\hline $\begin{array}{l}\text { Márcia Regina Aversani } \\
\text { Lourenço }\end{array}$ & $\begin{array}{l}\text { Tese - } \\
2015\end{array}$ & $\begin{array}{c}\text { A seleção brasileira de Ginástica Rítmica de } \\
\text { conjuntos: perfil de ginastas e treinadoras, } \\
\text { estrutura técnica e administrativa e o habitus } \\
\text { construído }\end{array}$ & História \\
\hline Franciny dos Santos Dias & $\begin{array}{c}\text { Dissertaçã } \\
0-2019\end{array}$ & $\begin{array}{l}\text { Garimpando memórias em busca de ouro: } \\
\text { histórias da Ginástica Rítmica no Espírito Santo }\end{array}$ & História \\
\hline $\begin{array}{l}\text { Gabriela Breggue Da Silva } \\
\text { Sampaio }\end{array}$ & $\begin{array}{l}\text { Dissertaçã } \\
0-2017\end{array}$ & $\begin{array}{l}\text { Formação de treinadores de Ginástica Rítmica: } \\
\text { perspectivas de aprendizagem ao longo da vida }\end{array}$ & $\begin{array}{l}\text { Formação } \\
\text { Profissional }\end{array}$ \\
\hline $\begin{array}{c}\text { Heloisa de Araujo Gonzalez } \\
\text { Alonso }\end{array}$ & $\begin{array}{c}\text { Dissertaçã } \\
0-1990\end{array}$ & $\begin{array}{l}\text { Do cognitivo ao fazer pedagógico - uma } \\
\text { proposta de avaliação do desempenho do futuro } \\
\text { docente em Ginástica Rítmica Desportiva }\end{array}$ & $\begin{array}{l}\text { Formação } \\
\text { Profissional }\end{array}$ \\
\hline Larissa Aurea Terezani & $\begin{array}{c}\text { Dissertaçã } \\
0-2007\end{array}$ & $\begin{array}{l}\text { (Des) Encontro de Gêneros na Ginástica } \\
\text { Rítmica: Um Estudo sobre Formação } \\
\text { Profissional em Educacão Física }\end{array}$ & $\begin{array}{l}\text { Formação } \\
\text { Profissional }\end{array}$ \\
\hline
\end{tabular}

Fonte: elaboração própria do(a/as/s) autor(a/as/es) (2020).

A determinação dos assuntos se deu pela leitura do título, palavras-chave e resumo. Os trabalhos com temas voltados a saúde são de cunho preventivo, recuperativo e nutricional que informam sobre determinados assuntos com o objetivo de melhorar a qualidade dos treinamentos, logo, a melhora da performance. Na perspectiva de estética como assunto principal, é perceptível visualizar o constante discurso da beleza de um corpo considerado "perfeito" dentro do subcampo da Ginástica Rítmica.

Ao analisar o conteúdo dos trabalhos classificados nestas duas temáticas, percebe-se que neles perpetuam a ideia de um estereótipo imposto pela modalidade e a necessidade de tratar certas condições de saúde na busca pela "perfeição". Consequentemente, essas teses e dissertações se enquadraram na dimensão de estética do Modelo Analítico dos 5E's (MARCHI JÚNIOR, 2015), que se vinculam nessa categoria pelo fato de suas narrativas permearem estereótipos de corpos ideais, metodologias de treinamentos, questões nutricionais e correlação do conceito de esporte e saúde.

Estética para Marchi Júnior (2015), pode estar associada a presença de estereótipos, ou melhor, dos padrões corporais de beleza impostos pela sociedade e perseguidos, em grande número de casos, de maneira patológica. Sendo assim, a ideia de beleza enfatizada nos trabalhos, ocorre pelo desejo do modelo de corpo esguio e longilíneo, padrão internacional de corpo das ginastas de alto nível que têm garantido as medalhas olímpicas (PORPINO, 2004). Para Boaventura (2016) as atletas de Ginástica Rítmica procuram a magreza e se sujeitam aos incômodos que ela impõe, como: aumentar o gasto energético, diminuir as porções e incluir alimentos "saudáveis". No entanto, essa forma restrita de se alimentar pode favorecer o aparecimento de lesões. Takada e Lourenço (2015) explicam que a dieta hipocalórica e um intenso gasto energético durante o treinamento físico e no 
próprio evento competitivo, podem se relacionar ao esgotamento das reservas de glicogênio e à fadiga, podendo acarretar lesões.

Portanto, os trabalhos que possuem a temática de saúde e de estética acerca da modalidade da GR, podem ser analisados através da dimensão estética do Modelo Analítico justamente por tratarem de fatores como alimentação, estereótipos e lesões advindas da prática. Dessa forma, no caso específico desta modalidade, a busca pelo corpo considerado "perfeito" junto a uma excelente performance, pode levar a ginasta ao encontro de uma radicalização na forma de se alimentar, no qual Vieira et al. (2009) aponta se tornar uma preocupação que pode gerar um processo emocional que leva a transtornos de conduta alimentares ou, ainda, a desordens alimentares.

Quando se refere ao assunto de treinamento, nota-se que existem as descrições de diferentes metodologias de treinamento e, dentre esses estudos, apenas um aborda a estrutura dos centros de treinamentos. Os temas ligados a história buscaram detalhar a trajetória da modalidade nas cidades/estados investigados. Já na perspectiva de formação profissional, existe um conteúdo comum dentre os trabalhos catalogados, sendo referente a qualificação dos professores da área da GR. Desse modo, essas temáticas podem ser enquadradas na dimensão educacional, por possuírem um mesmo objetivo em comum: informar sobre determinado conteúdo aos estudantes, técnicos e praticantes de Ginástica Rítmica.

Para Marchi Júnior (2015) a dimensão educacional deve interconectar com os demais "E's", ou seja, dialoga com a emoção, com a estética, com a ética ou com o espetáculo, sempre numa intencionalidade formativa. Sendo assim, quando tratamos de treinamento dentro desta dimensão, levando em considerações as teses e dissertações encontradas, conseguimos correlacionar as produções com as dimensões de estética e educação de forma concomitante, uma vez que a parte estética aparece devido ao estudo de metodologias de treinamento, como é o caso da dissertação da Cynthia Tibeau (1988), que se refere ao ensino da GR pelo método global, enquanto a parte educacional se sobressai por abordar trabalhos que contribuem para a formação e informação dos(as) leitores(as).

Já na correlação da temática de história, se encontram as dimensões de ética e educação. A perspectiva ética é perceptível até na leitura dos títulos desses trabalhos ${ }^{8}$. Observa-se que existe a narrativa acerca dos valores, condutas e regras da modalidade no local de estudo, sendo eles: como eram as regras da modalidade em determinado estado, quais foram os valores que a modalidade trouxe para a população daquela cidade, como foi o desenvolvimento da modalidade até o momento

\footnotetext{
${ }^{8}$ O trabalho de Lourenço (2003) também poderia ser considerado nessa dimensão. No entanto, ele não fez parte do escopo da presente investigação, visto que a dissertação não se encontra indexada nas bases de dados de teses e dissertações que foram utilizadas e descritas na metodologia.
} 
atual de cada estudo, entre outros. No entanto, quando se refere a dimensão educacional, ressalta-se que o objetivo central dessas produções é informar como foi a trajetória e como foi organizado o esporte nessas regiões, prezando principalmente o momento de formação das praticantes.

Assim como relacionado anteriormente, o tema de formação profissional está ligado às dimensões de ética e educação. Portanto, é possível correlacionar da mesma forma as duas perspectivas. A narrativa associada à dimensão ética neste tema, se volta exclusivamente para os valores, regras e condutas sobre a atuação do docente no ambiente de trabalho, por exemplo: entendimento do código de pontuação, condutas diante da pontuação aferida pelos árbitros, ensinamentos acerca dos valores morais e éticos que o esporte carrega, etc. Já os trabalhos mais voltados à dimensão educacional, tem seu enfoque numa narrativa formativa, informando ao leitor as maneiras de avaliações, como é o exemplo da dissertação da Heloisa Alonso (1990), na qual aplica uma avaliação de ensino-aprendizagem - que se dá através da descrição do domínio de conteúdo; aborda assuntos com pouco fomento no meio acadêmico como, por exemplo, meninos praticantes da modalidade; e descrevem alguns relatos de técnicos e ex-atletas da modalidade com o objetivo de informar como chegaram ao nível de alto rendimento, contando suas trajetórias.

Ademais, visualizou-se uma predominância nas temáticas de treinamento e saúde, porém, deixando evidente que além dessas predominâncias existe uma diversidade nas produções analisadas. Por ser uma modalidade relativamente nova para o Brasil, constata-se que estudiosos das áreas da Educação Física e da Fisioterapia têm se dedicado a estudar aspectos diversificados relacionados à Ginástica Rítmica, contribuindo para a disseminação do conhecimento acerca do esporte dentro e fora dessas áreas.

A utilização das dimensões do Modelo Analítico dos 5E's nas análises das produções de teses e dissertações que tiveram os assuntos mais tratados acerca da GR permitiu compreender a correlação existente nestes trabalhos entre o esporte e a sociedade - pois eles são produtos oriundos de análises das práticas dessa modalidade que passaram a se constituir como conhecimento teórico e científico. Assim sendo, as dimensões que interpretam os fenômenos esportivos nos possibilitaram visualizar e analisar de forma mais integrada essas produções.

\section{Conclusões}

O presente estudo buscou identificar o perfil da produção de teses e dissertações sobre a Ginástica Rítmica no Brasil. A delimitação espacial ocorreu devido ao crescimento e desenvolvimento da modalidade no país. Segundo Moraes et al. (2019), analisar como a GR vem se 
desenvolvendo no universo científico, se torna relevante para poder fomentar maiores discussões acerca da prática e, inclusive, incentivar pesquisadores interessados neste objeto a iniciarem outras pesquisas a partir das lacunas encontradas. Nesse sentido, buscou-se identificar as instituições que produziram estudos acerca deste esporte e quais as temáticas de maior interesse para os pesquisadores.

Foram encontradas 42 produções nas bases de dados da CAPES e da BDTD referentes a Ginástica Rítmica como objeto central de estudo, no período de 1988-2019. Dentre essas produções, 19 são oriundas da região sudeste e 17 da região sul, compondo 85,7\% das produções encontradas e os demais trabalhos foram realizados em diferentes regiões do país. As instituições de ensino com maior quantidade de pesquisas se encontram nestas regiões, sendo elas: Universidade Federal de Santa Catarina, Universidade Federal do Rio Grande do Sul e Universidade Estadual de Campinas. Após analisar cada uma dessas instituições, encontrou-se na plataforma online da UNICAMP um grupo de pesquisa com foco na ginástica (pela sua nomenclatura), não sendo especificamente da GR, mas abordando-a em suas palestras e reuniões. No entanto, é válido lembrar que apesar da localização desse lócus específico para o debate sobre a ginástica, salientamos que não foram examinadas iniciativas das instituições investigadas em relação aos projetos de extensão oferecidos - ações comuns nas universidades. A presente pesquisa, visto essa limitação, abre espaço para que investigações sobre como tem se debatido e promovido a GR em instituições de formação superior sejam realizadas futuramente.

Ao identificar as temáticas de maior interesse dos pesquisadores, encontrou-se a predominância de assuntos vinculados a saúde e treinamento, possivelmente pela GR se constituir como uma modalidade competitiva e fazer parte do currículo do curso de Educação Física - o qual faz parte do setor de Ciências Biológicas das instituições, na maioria dos casos. Os cursos de PósGraduação em Educação Física - sendo esses os principais produtores de teses e dissertações sobre GR - pertencem e são avaliados pela área 21 da CAPES, com produções diversificadas, indo das áreas biológicas até as áreas das humanidades, mas ainda com a predominância da produção voltada aos aspectos biológicos (LAZZAROTTI FILHO et al., 2018).

Mesmo que essas duas temáticas estejam mais voltadas aos aspectos biológicos, quando foram analisadas as produções sobre treinamento, notou-se que esses estudos possuíam um viés pedagógico direcionado a treinadores e professores de GR. Sendo assim, ao ser realizada a leitura através do Modelo Analítico dos 5E’s (Marchi Júnior, 2015) optou-se pela associação à dimensão educacional e não da estética, pois a dimensão educacional compreende o fenômeno esportivo de maneira ampla, conversando com as demais dimensões para auxiliar nessa análise. Assim, a temática do treinamento, ao observarmos as teses e dissertações, tem ligações com essa dimensão, pois consegue, a partir 
desses trabalhos e até mesmo pela prática (da docência e aprendizagem), transmitir particularidades educacionais da modalidade.

Na dimensão Estética foram analisados os assuntos relacionados a saúde e estética, visto que suas narrativas permeiam a estereótipos de corpos ideais, metodologias de treinamentos, questões nutricionais e correlação do conceito de esporte e saúde. Para Marchi Júnior tal dimensão trata dos discursos que associam o esporte com o conceito de saúde e que apresenta de maneira obsessiva a busca pelo corpo perfeito, com o objetivo de se enquadrar nos padrões estéticos ditados pela sociedade. Portanto, trabalhos que possuam a temática de saúde e de estética acerca da modalidade da GR, podem ser analisados através da dimensão estética do Modelo Analítico justamente por tratar de fatores como alimentação, estereótipos e lesões advindas da prática.

As temáticas de história e formação profissional também foram exploradas através do Modelo Analítico, sendo analisadas pela dimensão Educacional juntamente com a Ética. A escolha de correlacionar essas dimensões ocorreu após visualizar nas pesquisas que a ética e a educação se mostravam presentes nas narrativas desses trabalhos com abordagens mais socioculturais e pedagógicas, possivelmente porque temas com essas linhas de pesquisa voltadas às modalidades esportivas, tendem a abordar as regras, valores e condutas dentro dos seus textos, sendo esse o motivo para classificá-los na dimensão da educação e da ética.

Torna-se oportuno mencionar que as limitações práticas deste estudo foram devidas as delimitações nas buscas das teses e dissertações apenas nos bancos de dados da CAPES e da BDTD. As buscas em outras bases ampliariam os resultados, sendo uma das sugestões de prosseguimento da pesquisa. Ainda, a codificação de assuntos também pode ser elencada como uma limitação de estudo, bem como a sua classificação ao analisar a produção por meio do Modelo Analítico - mas também é considerada uma delimitação necessária para apresentar um panorama sobre a produção analisada.

Sendo assim, entende-se que novos caminhos para este tipo de pesquisa poderão se desenvolver no meio acadêmico, visto que o crescimento da modalidade tem sido acentuado no país, favorecendo novos olhares e perspectivas acerca da GR e a produção de conhecimento científico sobre a modalidade no Brasil. Uma recomendação para estudos futuros, seria avançar as análises a partir do aprofundamento teórico em cada dimensão abordada na pesquisa. Para isso, a utilização de leituras específicas de autores que tratam exclusivamente a estética, da ética, e assim por diante, por exemplo, poderão oferecer um olhar mais profundo sobre essas teses e dissertações.

Desse modo, considera-se que o presente estudo pôde contribuir para o meio acadêmico ao mapear as teses e dissertações produzidas no Brasil que focam a Ginástica Rítmica evidenciando, inclusive, as vertentes menos investigadas como assuntos envolvendo políticas públicas, lazer, inclusão, entre outros temas passíveis de serem pesquisados e que não foram localizados. Por fim, 
conclui-se que este estudo oferece subsídios metodológicos para a ampliação deste quadro atual das produções sobre a GR e fomenta a produção de conhecimento sobre esse objeto de estudo.

\section{REFERÊNCIAS}

ALONSO, Heloisa de Araujo Gonzalez. Do cognitivo ao fazer pedagógico - uma proposta de avaliação do desempenho do futuro docente em Ginástica Rítmica Desportiva. 1990. 126 f. Dissertação (Mestrado) Curso de Pós-Graduação em Educação, Universidade Federal do Rio de Janeiro, Rio de Janeiro, 1990.

ANTUALPA, Kizzy Fernandes. Centros de treinamento de Ginástica Rítmica no Brasil: estrutura e programas. 2011. 188 f. Dissertação (Mestrado) - Pós-Graduação da Faculdade de Educação Física, Universidade Estadual de Campinas, Campinas, 2011.

BOAVENTURA, Patrícia Luiza Bremer. Técnica, estética, educação: os usos dos corpos na Ginástica Rítmica. 2016. 445 f. Tese (Doutorado) - Programa de Pós-Graduação Interdisciplinar em Ciências Humanas, Universidade Federal de Santa Catarina, Florianópolis, 2016.

BOURDIEU, Pierre. Coisas ditas. São Paulo: Brasiliense S. A., 1990.

BOURDIEU, Pierre. Razões práticas. Campinas: Papirus, 1996.

BOURDIEU, Pierre. Questões de sociologia. Lisboa: Fim de século, 2003.

BOURDIEU, Pierre. O campo científico. In: ORTIZ, Renato (org.). A sociologia de Pierre Bourdieu. São Paulo: Olho d'Água, 2003, p. 112-143.

BOURDIEU, Pierre. O senso prático. 3 ed. Petropolis: Vozes, 2009.

CARDOSO, Thays Caroline dos Santos. Ginástica Rítmica e especialização precoce: caminhos das pesquisas e publicações no Brasil. 2013. 62 f. Trabalho de conclusão de curso (Graduação em Educação Física) - Curso de Educação Física, Universidade Estadual Paulista, Rio Claro, 2013.

DART, Jonathan. Sports review: A content analysis of the International Review for the Sociology of Sport, the Journal of Sport and Social Issues and the Sociology of Sport Journal across 25 years. International

Review For The Sociology Of Sport, [S. 1.], p. 645-668. nov. 2014. Disponível em: https://journals.sagepub.com/doi/10.1177/1012690212465736. Acesso em: 20 julho 2021.

FERMINO, Antônio Luis; VELASCO, Amanda; TRINDADE, Nadyne Venturini; SOUZA, Doralice Lange de; MARCHI JÚNIOR, Wanderley. ESPORTE PARALÍMPICO: análise da produção de teses e dissertações dos programas de pós-graduação em educação física. Revista Brasileira de Ciência e Movimento, Brasília, v. 26, n. 3, p. 165-177, 15 nov. 2018. Universidade Católica de Brasília. Disponível em: http://dx.doi.org/10.31501/rbcm.v26i3.7308. Acesso em: 20 julho 2021.

GIL, Antonio Carlos. Métodos e técnicas de pesquisa social. 6. ed. São Paulo: Atlas S.A, 2008.

LOURENÇO, Márcia Regina Aversani. A seleção brasileira de conjuntos de Ginástica Rítmica: perfil de ginastas e treinadoras, estrutura técnica e administrativa e o habitus construído. 2015. $190 \mathrm{f}$. Tese (Doutorado em Educação Física) - Programa de Pós-Graduação em Educação Física, Universidade Federal de Maringá, Maringá, 2015. 
LOURENÇO, Márcia Regina Aversani. Ginástica Rítmica no Brasil: A (R)evolução de um esporte. 2003. 176 f. Dissertação (Mestrado) - Curso de Educação Física, Universidade Metodista de Piracicaba, Piracicaba, 2003.

MARCHI JÚNIOR, Wanderley. O esporte "em cena": perspectivas históricas e interpretações conceituais para a construção de um modelo analítico. The Journal Of The Latin American Socio-Cultural Studies Of Sport, Curitiba, p. 46-67. jan. 2015. Disponível em: https://revistas.ufpr.br/alesde/article/view/43890. Acesso em: 20 julho de 2021.

MARCHI JÚNIOR, Wanderley. Campo esportivo. In: CATANI, Afrânio Mendes et al. (org.). Vocabulário Bourdieu. Belo Horizonte: Autêntica Editora, 2017, p. 79-81.

MAZZEI, Leandro Carlos; BASTOS, Flavia; FERREIRA, Raimundo Luiz; BÖHME, Maria Tereza Silveira. Centros de Treinamento Esportivo para o Esporte de Alto Rendimento no Brasil: Um Estudo Preliminar. Revista Mineira de Educação Física, Viçosa, v. 3, n. 1, p. 1575-1584, jan. 2012. Disponível em: http://cev.org.br/arquivo/biblioteca/4024105.pdf. Acesso em: 20 julho 2021.

MORAES, Leticia Cristina Lima; SILVA, Marcelo Moraes e; RINALDI, Ieda Parra Barbosa; ROJO, Jeferson Roberto; GOMES, Leonardo do Couto. Ginástica Rítmica: Perfil sobre a produção científica em periódicos da América Latina, Caribe e Países Ibéricos. Pensar En Movimiento: Revista de Ciencias del Ejercicio y La Salud, San José, v. 17, n. 1, p. 1-23, jan. 2019. Disponível em: https://www.scielo.sa.cr/scielo.php?script=sci abstract\&pid=S1659-

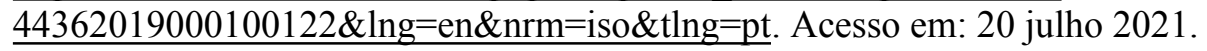

PAZ, Bruna; SOUZA, Juliano de; BARBOSA-RINALDI, Ieda Parra. A constituição de um subcampo esportivo: o caso da Ginástica Rítmica. Movimento, Porto Alegre, v. 24, n. 2, 2018. Disponível em: https://seer.ufrgs.br/Movimento/article/view/73658/48691. Acesso em: 26 julho 2021.

PORPINO, Karenine de Oliveira. Treinamento Da Ginástica Rítmica: Reflexões Estéticas. Revista Brasileira de Ciencias do Esporte, São Paulo, v. 26, n. 1, p. 121-133, jul. 2004. Disponível em: http://revista.cbce.org.br/index.php/RBCE/article/view/108. Acesso em: 20 julho 2021.

SIMÕES, Regina; MOREIRA, Wagner Wey; CHAVES, Aline Dessupoio; SANTOS, Suziane Peixoto; COELHO, Ana Laura; CARBINATTO, Michele Viviane. A produção acadêmica sobre ginástica: estado da arte dos artigos científicos. Revista Brasileira de Educação Física e Esporte, São Paulo, v. 30, n. 1, p. 183198, mar. 2016. FapUNIFESP (SciELO). Disponível em: http://dx.doi.org/10.1590/180755092016000100183. Acesso em: 25 julho 2021.

TAKADA, Sheilla Regina; LOURENÇO, Márcia Regina Aversani. Menarca tardia e osteopenia em atletas de Ginástica Rítmica: uma visão de literatura. Journal Of Health Scienses, Londrina, p. 41-47, jul. 2015. Disponível em: https://revista.pgsskroton.com/index.php/JHealthSci/article/view/1636. Acesso em: 20 julho 2021.

VIEIRA, José Luiz Lopes; AMORIM, Helenice Zotto; VIEIRA, Lenamar Fiorese; AMORIM, Adolpho Cardoso; ROCHA, Priscila Garcia Marques da. Distúrbios de atitudes alimentares e distorção da imagem corporal no contexto competitivo da Ginástica Rítmica. Revista Brasileira de Medicina do Esporte, São Paulo, v. 15, n. 6, p. 410-414, dez. 2009. Disponível em: http://dx.doi.org/10.1590/s151786922009000700001. Acesso em: 20 julho 2021.

WACQUANT, Loïc. Mapear o campo artístico. Sociologia, Problemas e Práticas, Lisboa, n. 48, p. 117123, 2005. Disponível em: https://sociologiapp.iscte-iul.pt/pdfs/48/516.pdf. Acesso em: 26 julho 2021. 


\section{NOTAS DE AUTOR}

CONTRIBUIÇÃO DE AUTORIA: não se aplica.

FINANCIAMENTO: não se aplica.

CONSENTIMENTO DE USO DE IMAGEM: não se aplica.

APROVAÇÃO DE COMITÊ DE ÉTICA EM PESQUISA: não se aplica

CONFLITO DE INTERESSES

Não há conflitos de interesse.

\section{LICENÇA DE USO}

Os autores cedem à Motrivivência - ISSN 2175-8042 os direitos exclusivos de primeira publicação, com o trabalho simultaneamente licenciado sob a Licença Creative Commons Attribution Non-Comercial ShareAlike (CC BY-NC SA) 4.0 International. Esta licença permite que terceiros remixem, adaptem e criem a partir do trabalho publicado, desde que para fins não comerciais, atribuindo o devido crédito de autoria e publicação inicial neste periódico desde que adotem a mesma licença, compartilhar igual. Os autores têm autorização para assumir contratos adicionais separadamente, para distribuição não exclusiva da versão do trabalho publicada neste periódico (ex.: publicar em repositório institucional, em site pessoal, publicar uma tradução, ou como capítulo de livro), com reconhecimento de autoria e publicação inicial neste periódico, desde que para fins não comerciais e compartilhar com a mesma licença.

\section{PUBLISHER}

Universidade Federal de Santa Catarina. Programa de Pós-Graduação em Educação Física. LaboMídia - Laboratório e Observatório da Mídia Esportiva. Publicado no Portal de Periódicos UFSC. As ideias expressadas neste artigo são de responsabilidade de seus autores, não representando, necessariamente, a opinião dos editores ou da universidade.

\section{EDITORES}

Mauricio Roberto da Silva, Giovani De Lorenzi Pires, Rogério Santos Pereira.

\section{EDITOR DE SEÇÃO}

Silvan Menezes dos Santos

REVISÃO DO MANUSCRITO E METADADOS

João Caetano Prates Rocha; Keli Barreto Santos; Juliana Rosário.

\section{HISTÓRICO}

Recebido em: 26 maio 2021

Aprovado em: 25 novembro 2021 